\title{
Should we always perform bulbar biopsies in celiac disease?
}

\author{
Aomari A, Benelberhdadi I, Firwana $\mathrm{M}^{*}$, and Ajana FZ \\ Department of Diseases of the Digestive System, Medicine C, CHU IBN SINA-University Souissi Med V- Rabat, Morocco
}

\section{Introduction}

Celiac disease (CD) is an autoimmune inflammatory enteropathy that corresponds to an inappropriate mucosal immune response to gluten proteins. His diagnosis is mainly based on histological lesions at the 2 nd and 3rd duodenum. The aim of this work is to check if bulbar biopsies can improve the diagnosis of this disease.

\section{Patients and methods}

This is a descriptive and analytical retrospective study that includes patients with certain celiac disease and in whom both bulbar biopsies and duodenal biopsies were performed.

\section{Results}

For a total of 284 patients followed for celiac disease, 44 patients meet the inclusion criteria. The average age of patients was 37.9 years [14-70]. There were 46 women and 15 men with a sex ratio $\mathrm{F} / \mathrm{H} 3.6$. Clinically, $68.18 \%$ had chronic diarrhoea and abdominal pain, $23 \%$ had isolated abdominal pain and $14 \%$ had an isolated anaemic syndrome. Upper gastrointestinal fibroscopy regained an appearance suggestive of celiac disease in $75 \%$. The histological study showed an isolated bulbar wait with intraepithelial lymphocytosis (IEL) $>30 \%$ and villous atrophy in 5 cases $(8.1 \%)$. The duodenum involvement associated with bulbar involvement was found in the rest of the patients, 56 cases (91\%). It should be noted that in 09 cases (14\%) the IEL was more marked at the bulbar than at the duodenal level.

\section{Discussion}

The diagnosis of celiac disease is confirmed by the demonstration of inflammatory changes in the small intestinal villi. Since the duodenum and the proximal jejunum are exposed to the highest concentration of gluten, changes are more marked in the proximal small intestine than the distal. In the past, distal duodenal/upper jejunal biopsy was obtained using Crosby-Watson capsule. However, with fibreoptic endoscopy, the duodenum is much more easily accessible for mucosal biopsies. Multiple biopsies are recommended to help reduce the chances of insufficient tissue for histological assessment. Biopsies should be taken even if the duodenal mucosa grossly appears normal as histology may reveal disease in these cases [1]. Traditionally, for celiac disease, biopsies from the duodenal bulb have not been recommended on the assumption that the histology from this area may be difficult in interpret. The bulb contains more Brunner's glands and lymphoid tissue and can have gastric metaplasia compared to the distal duodenum [2]. The villi may also be shorter and broader in this area [3,4]. Duodenitis from other causes may also interfere with interpretation of villous atrophy in this region. The current guidelines by the professional gastroenterological organizations including American Gastroenterological Association (Technical Review 2006), North American Society for Paediatric
Gastroenterology, Hepatology and Nutrition (Practice Guidelines 2005) and World Gastroenterology Organization (Practice Guidelines 2007) recommend four biopsies to be taken from the distal duodenum for histological examination in celiac disease [5]. Since the first classification of the spectrum of villous lesions in celiac disease by Marsh [6], there have been several modifications to this criterion. Counting of IELs can improve the diagnostic yield when the typical villous atrophy is not present or not detectable due to poor orientation or tangential cutting. The patchy nature of the small intestinal lesion in celiac disease is increasingly being recognized both in children and adults [7-11]. The patchiness of lesion in various parts of the duodenum can be in terms of absence or presence of villous atrophy [11] or in the severity of atrophy [5]. Since the treatment of celiac disease requires a lifelong, strict adherence to gluten-free diet, making a definitive diagnosis of the disorder is of great importance. In an earlier study, Bonamico et al. [12] demonstrated the patchy nature of the lesion in celiac disease both in children who were newly diagnosed and those on a gluten challenge. In all 95 children at the time of diagnosis of celiac disease, the bulbar mucosa was involved showing varying degrees of type 3 villous atrophy. In four (4.2\%) patients, the bulb was the only duodenal area involved with the other duodenal samples being normal. Prasad et al have reported similar findings of duodenal bulb involvement [8]. In 52 children with suspected celiac disease who underwent one bulb and one distal duodenal biopsy, all had Marsh type 3 lesions in at least one of the sites. The authors concluded that duodenal bulb biopsy was equally diagnostic of celiac disease. More recently, in a large Italian study of children with celiac disease the duodenal bulb was involved in all cases of and in some patients the lesion was only presented in the bulb with distal duodenum being normal [9]. Villous atrophy limited to duodenal bulb has also been described in adults with celiac disease $[10,11]$. Based on the current and previous studies, we recommend that biopsies should be taken both from the bulbar and the distal duodenal mucosa, as these will complement each other in confirming the diagnosis of celiac disease. Accepting that villi in the bulb may be less tall, increased IELs in the presence of a positive serological test will help improve the likelihood of the diagnosis of celiac disease. We concur with the suggestion by Hopper et al that multiple biopsy strategy should incorporate a biopsy from the duodenal bulb [13]. Moreover, the bulb should be biopsied irrespective of its gross appearance. We speculate that some patients considered to have a "false-positive" serological test may, in fact, truly have celiac disease. The diagnosis could have been

${ }^{*}$ Correspondence to: Mohammed Firwana, Department of Diseases of the Digestive System, Medicine C, CHU Ibn Sina, Mohamed V University, Souissi, Rabat, Morocco, Tel: 212 679615807; E-mail: medfirwana7@gmail.com

Received: February 05, 2019; Accepted: February 21, 2019; Published: February 26,2019 
missed in these cases as the biopsies are taken routinely only from the distal duodenum and not from the bulb.

\section{Conclusion}

Bulbar biopsies made it possible to establish the diagnosis of celiac disease in $8.1 \%$ of cases, which justifies their achievement in this disease.

\section{References}

1. Brocchi E, Tomassetti P, Misitano B, Epifanio G, Corinaldesi R, et al. (2002) Endoscopic markers in adult coeliac disease. Dig Liver Dis 34: 172-174. [Crossref]

2. Holdstock G, Eade OE, Isaacson P, Smith CL (1979) Endoscopic duodenal biopsies in coeliac disease and duodenitis. Scand J Gastroenterol 14: 717-720. [Crossref]

3. Segal GH, Petras RE (1992) Small Intestines. Histology for Pathologists. New York: Lippincott Raven: 558-561.

4. Korn ER, Foroozan P (1974) Endoscopic biopsies of normal duodenal mucosa. Gastrointest Endosc 21: 51-54. [Crossref]

5. http://www.worldgastroenterology.org/guidelines/global-guidelines/celiac-disease

6. Marsh MN (1992) Gluten, major histocompatability complex and the small intestine. A molecular and immunobiologic approach to the spectrum of gluten sensitivity ("celiac sprue"). Gastroenterolgy 4: 667-673. [Crossref]
7. Ravelli A, Bolognini S, Gambarotti M, Villanacci V (2005) Variability of histologic lesions in relation to biopsy site in gluten-sensitive enteropathy. Am J Gastroenterol 100: 177-185. [Crossref]

8. Prasad KK, Thapa BR, Nain CK, Singh K (2009) Assessment of the diagnostic value of duodenal bulb histology in patients with celiac disease, using multiple biopsy sites. J Clin Gastroenterol 43: 307-311. [Crossref]

9. Bonamico M, Thanasi E, Mariani P, Nenna R, Luparia RP, et al. (2008) Duodenal bulb biopsies in celiac disease: a multicenter study. J Pediatr Gastroenterol Nutr 47: 618622. [Crossref]

10. Brocchi E, Tomassetti P, Volta U, Piscitelli L, Bonora M, et al. (2005) Adult coeliac disease diagnosed by endoscopic biopsies in the duodenal bulb. Eur J Gastroenterol Hepatol 17: 1413-1415. [Crossref]

11. Vogelsang H, Hänel S, Steiner B, Oberhuber G (2001) Diagnostic duodenal bulb biopsy in celiac disease. Endoscopy 33: 336-340. [Crossref]

12. Bonamico M, Mariani P, Thanasi E, Ferri M, Nenna R, et al. (2004) Patchy villous atrophy of the duodenum in childhood celiac disease. J Pediatr Gastroenterol Nutr 38: 204-247. [Crossref]

13. Hopper AD, Cross SS, Sanders DS (2007) Patchy villous atrophy in adult patients with suspected gluten-sensitive enteropathy: is a multiple duodenal biopsy strategy appropriate? Endoscopy 39: 219-224. [Crossref]

Copyright: @2019 Aomari A. This is an open-access article distributed under the terms of the Creative Commons Attribution License, which permits unrestricted use, distribution, and reproduction in any medium, provided the original author and source are credited. 